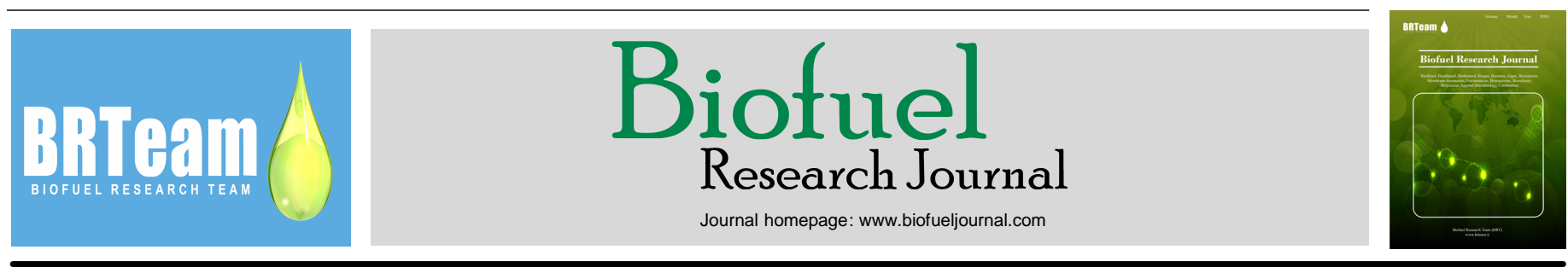

Editorial

\title{
Biofuel Research Journal: a story of continuing success
}

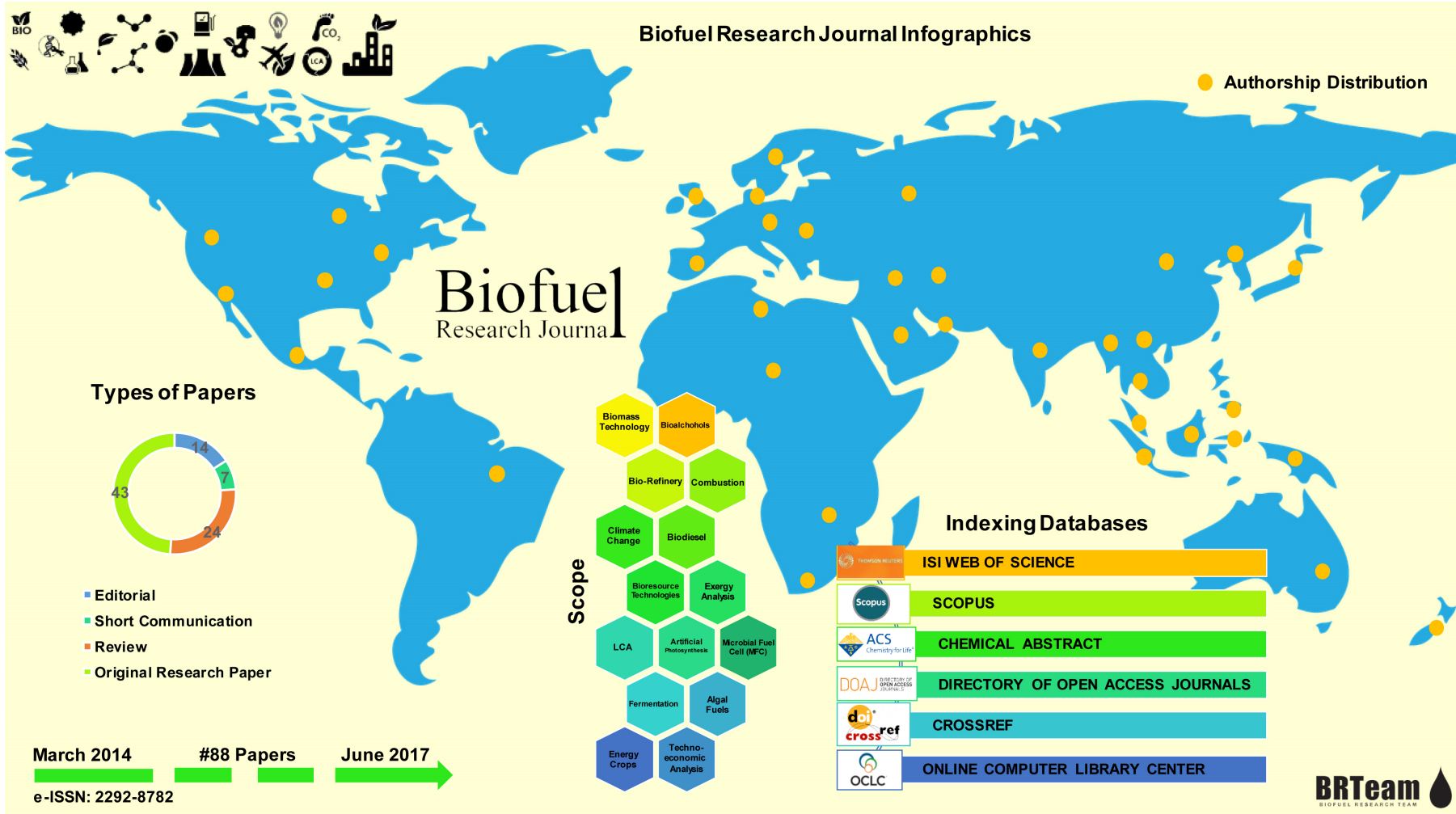

Biofuel Research Journal (BRJ) was launched in March 2014 as an open access, online and no-cost medium for dissemination of biofuels research in all its diversity (Tabatabaei et al., 2014).

Since its launch, the journal has been overwhelmed with submissions from around the world. This can be attributed to the unique features the journal offers, including open-access at no-charge and a strong international editorial board. The current editorial board includes editors and chief editors of several other prestigious high-impact journals, including Biorsource Technology, Water Research, Biotechnology Advances, Applied Energy, Desalination, Industrial Crops and Products, Journal of Biomass to Biofuel, International Journal of Hydrogen Energy, BioEnergy Research Journal, BioResources, Energy \& Environmental Science, MethodsX, Journal of Membrane Science, Chemical Engineering Science, Catalysis Today, ACS Catalysis, and others.
All papers accepted by BRJ receive the benefit of a completely free professional English language editing service. So far, BRJ has published 14 editorials, 7 short communications, 24 reviews, and 43 original research papers. These items have covered a wide range of topics - biodiesel, fuel alchohols, biogas, biohydrogen, energy crops, microbial fuel cells, life cycle assessment of biofuel production, artificial photosynthesis, biomass processing, pyrolysis, membrane-assisted solutions, climate change, and others. Authors from more than 30 countries have contributed to the journal indicating a strong global interest in the journal.

BRJ is now indexed by Thomson Reuters Web of Science Emerging Sources Citation Index, Scopus, CrossRef, Directory of Open Access Journals (DOAJ), and other databases.

The papers published in BRJ have been downloaded a staggering 300,000+

Copyright $(2017$ Published by BRTeam

Please cite this article in press as: Tabatabaei M, Chisti Y, Ismail AF, Ramakrishna S. Biofuel Research Journal: an endless success story. Biofuel Research Journal 14 (2017) 571-572. DOI: 10.18331/BRJ2017.4.2.2 
times and according to Google Scholar have received over 700 citations. These indices attest to the high scientific quality of the published material. A rigorous review process has been important in this achievement and we are grateful to the many anonymous reviewers who have contributed to this. As in the past, BRJ will continue to have a multidisciplinary focus within the domain of biofuels. In addition to shorter communications, reviews and full research papers, we plan to publish short "hypothesis" papers in some of the future issues. All submissions will continue to face a demanding peer review process. We seek scientifically-grounded papers discussing "futuristic" pathways for biofuels production and impact of all aspects of biofuels on climate.

This is the fourteenth issue of the journal. We hope you like it and count on your continuing support in the future.

\section{References}

[1] Tabatabaei, M., Chisti, Y., Ismail, A.F., Ramakrishna, S. 2014. Editorial. Biofuel Res. J. 1, 1.

Editor-in-Chief

Meisam Tabatabaei

Biofuel Research Team (BRTeam), ABRII, Iran

International Advisory Board Members

Yusuf Chisti

Massey University, New Zealand

Ahmad Fauzi Ismail

Universiti Teknologi Malaysia (UTM), Malaysia

Seeram Ramakrishna National University of Singapore (NUS), Singapore

Email Addresses: meisam_tabatabaei@abrii.ac.ir (M. Tabatabaei) y.chisti@massey.ac.nz. (Y.Chisti) afauzi@utm.my (A.F. Ismail) seeram@nus.edu.sg (S. Ramakrishna) 